\title{
Pelvic Intravenous Leiomyomatosis - Case Report
}

\section{Leiomiomatose intravenosa pélvica - caso clínico}

\author{
Patricia Correia ${ }^{1}$ Ana Castro ${ }^{1}$ Anabela Rocha ${ }^{2}$ Daniela Freitas $^{1}$ Cátia Carnide ${ }^{1}$ Osvaldo Moutinho ${ }^{1}$ \\ 1 Department of Gynecology and Obstetrics, Centro Hospitalar de \\ Address for correspondence Patricia Correia, Resident Doctor, \\ Trás-os-Montes e Alto Douro (CHTMAD), Lordelo, Vila Real, Portugal \\ 2 Department of Gynecology and Obstetrics, Centro Hospitalar de S. \\ Avenida da Galiza, Ed. Miradouro, Bloco B, $5^{\circ}$ Dto., 5050-222, Régua, \\ Portugal (e-mail: pattricia.ramos.correia@gmail.com).
}

João, Porto, Portugal

Rev Bras Ginecol Obstet 2016;38:412-415.

\begin{abstract}
\section{Keywords}

- intravenous leiomyomatosis

- uterine leiomyoma

- pelvic mass
\end{abstract}

\section{Resumo}

\section{Palavras-chave}

- leiomiomatose intravenosa

- leiomioma uterino

- massa pélvica
Introduction Intravenous leiomyomatosis is a benign and rare condition that can result in cardiac events with fatal outcomes when left untreated. Intravenous leiomyomatosis is probably underestimated because the diagnosis is easily missed. We present a case of an intravenous leiomyomatosis without extra-pelvic involvement, with a brief review of this pathology.

Case Report 46-year-old woman submitted to hysterectomy and bilateral adnexectomy because of a pelvic mass detected in ultrasound. During the surgery, intravenous leiomyomatosis diagnosis was suspected. Pathological analysis confirmed this suspicion. Further imaging exams were performed without detecting any anomalies related to this condition. The patient remained with no evidence of disease after one year of follow-up.

Conclusion Intravenous leiomyomatosis is a rare condition that can lead to serious complications. Early diagnosis followed by an appropriate treatment is very important to patient outcome, and underdiagnoses can be counteracted if the gynecologist is aware of this entity.

Introdução A leiomiomatose intravenosa é uma condição benigna, rara, que pode resultar em eventos cardíacos, podendo ser fatal quando não tratada. Esta patologia está provavelmente subestimada, uma vez que facilmente não é diagnosticada. Neste artigo, apresentamos um caso de leiomiomatose intravenosa sem envolvimento extrapélvico, com uma breve revisão da patologia.

Relato de Caso Mulher de 46 anos de idade, submetida a histerectomia e anexectomia bilateral após detecção ecográfica de massa pélvica. Durante a cirurgia, houve a suspeita de leiomiomatose intravenosa, e o exame anátomo-patológico confirmou o diagnóstico. A paciente foi submetida a outros exames de imagem, não sendo detectada qualquer anomalia relacionada com a patologia. Após um ano de followup, a paciente manteve-se sem evidência de doença.

Conclusão A leiomiomatose intravenosa é uma condição rara que pode levar a complicações graves. O diagnóstico precoce e o tratamento adequado são muito importantes para o prognóstico da paciente, e os subdiagnósticos podem ser evitados se o ginecologista estiver ciente dessa entidade. received

February 15, 2016

accepted

July 12,2016

published online

August 16, 2016
DOI http://dx.doi.org/

10.1055/s-0036-1588002.

ISSN $0100-7203$.
Copyright $\odot 2016$ by Thieme Publicações License terms

Ltda, Rio de Janeiro, Brazil $\circledast(1) \Theta$ 


\section{Introduction}

Uterine leiomyomas affect $20-40 \%$ of women in reproductive age. ${ }^{1}$ Occasionally, they occur with unusual growth patterns, including intravenous leiomyomatosis (IVL), diffuse peritoneal leiomyomatosis, benign metastasizing leiomyomas, retroperitoneal leiomyomas and parasitic leiomyomas.

Intravenous leiomyomatosis is a benign and rare condition that, when left untreated, can result in cardiac events with fatal outcomes. ${ }^{2,3}$ Histologically, it is a benign smooth muscle cell tumor growing within the uterine venous system, sometimes extending to the inferior vena cava and to the right cardiac chambers. There are two main theories about the etiology of this tumor: one contends that the tumor grows from the vein wall; the other suggests that the tumor is a uterine leiomyoma invading the vessels. ${ }^{4}$

Until 2010, there were 298 reported cases of IVL in the English literature, and in $45 \%$ of these cases the tumor penetrated to the inferior vena cava or reached the right atrium. ${ }^{5}$ The occurrence of IVL is probably underestimated because the diagnosis is easily missed. ${ }^{5}$ This reported case emphasizes the importance of prompt diagnosis to perform a correct treatment and follow-up, ensuring a minimized risk of recurrence.

\section{Case Report}

A 46-year-old woman, multigravida, parous 5, obese, without any history of pathologic events, who presented regular cycles, with abundant menses, and non-cyclic pelvic pain. She was referred to our hospital for gynecological consultation because of a pelvic mass detected in a pelvic ultrasound.

The gynecological examination revealed a 12-week uterus without any other palpable masses. The transvaginal ultrasound showed a uterus with augmented dimensions, with the external limits deformed by multiple leiomyomas, the larger of which measured $33 \times 28 \times 16 \mathrm{~mm}$ in intramural/ subserous localization. Right adnexal area: complex hetero-

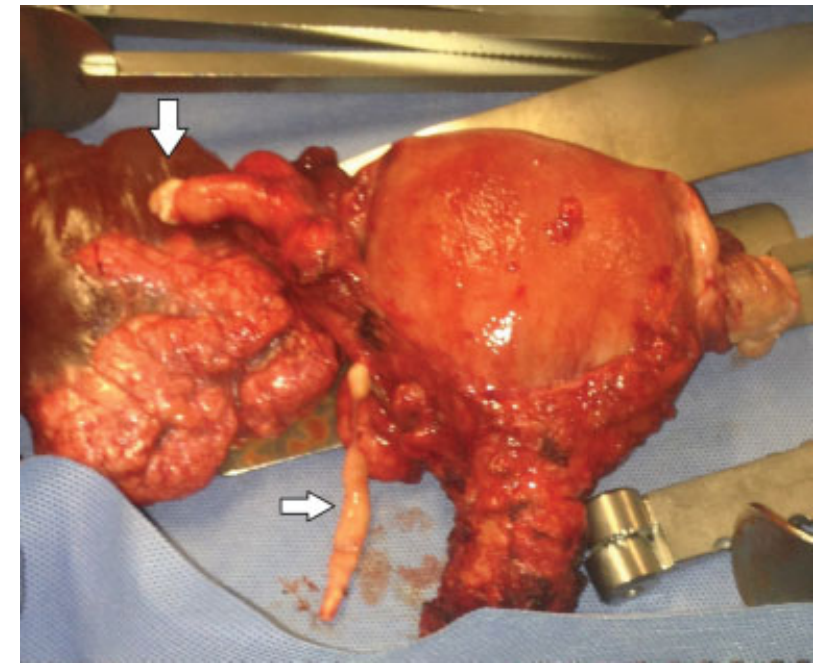

Fig. 1 Uterus and bilateral adnexa with a right paraovarian mass and intravenous leiomyomatosis in the right uterine and right ovarian veins (arrows).

geneous mass, with a cystic bi-loculated component, measuring $100 \times 91 \times 52 \mathrm{~mm}$, the major one measuring. measuring $67 \times 46 \mathrm{~mm}$, and two solid components with $50 \times 17 \mathrm{~mm}$ and $18 \times 10 \mathrm{~mm}$, respectively, without vascularization on Doppler exam. There were no ascites. Cancer antigen 125 (CA 125) was normal. The patient was submitted to an exploratory laparotomy.

Surgical findings included a large uterus, with three subserous fibroids; the ovaries and fallopian tubes were macroscopically normal. A $100 \mathrm{~mm}$ right paraovarian mass was identified, both cystic and solid, extending from the infundibulopelvic ligament to the paracervix (-Figs. 1 and 2). This white-gray elastic mass was enucleated and removed. Smaller pieces with the same appearance (wormlike) were easily extracted from the right uterine and right ovarian veins ( $\mathbf{- F i g . ~ 1 ) . ~ H y s t e r e c t o m y ~ a n d ~ b i l a t e r a l ~ a d n e x - ~}$ ectomy were executed.

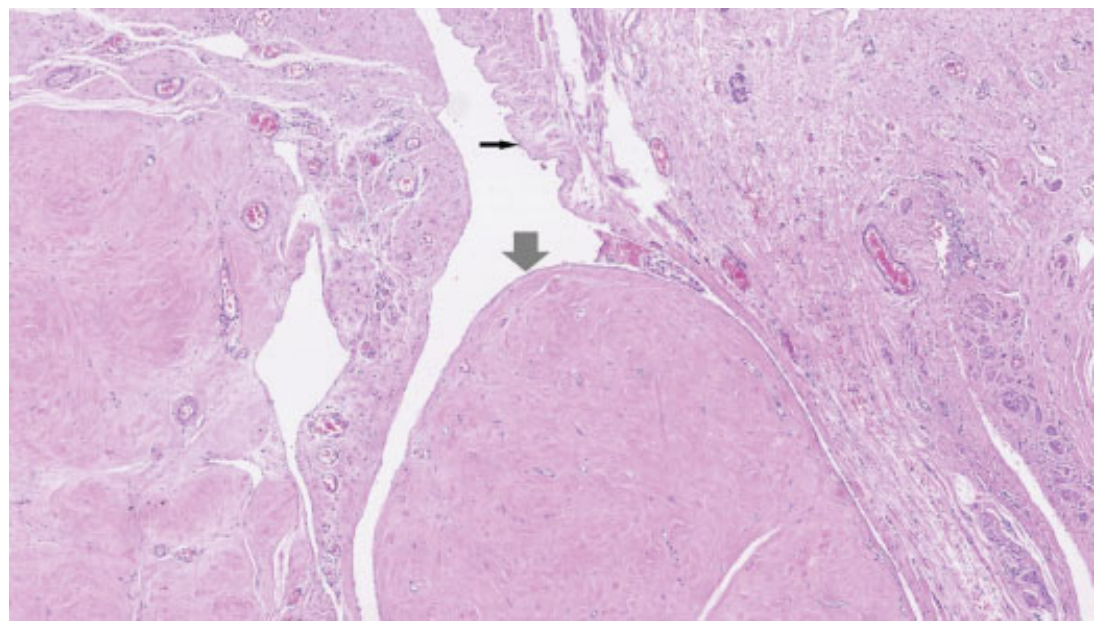

Fig. 2 Histological findings revealing intravenous leiomyomatosis (large arrow) inside the ovarian vein (straight arrow points to vein endothelium). 
Pathological analysis confirmed IVL and uterine leiomyomas (-Fig. 2).

The patient had an uneventful post-operative recovery. Further investigations with pelvic magnetic resonance imaging (MRI), thoracic-abdominopelvic computed tomography (CT) and echocardiogram were carried, without detecting any anomaly related to IVL. The patient started a continuous progestative treatment, and remained without signs of disease after one year of follow-up.

\section{Discussion}

Intravenous leiomyomatosis usually affects premenopausal women with a median age of 43-45 years in most studies (range between 20-81). ${ }^{4-6}$

The clinical manifestations of IVL are very unspecific and usually asymptomatic in early stages. ${ }^{4,5,7}$ Women can present symptoms related to the pelvic mass, like abdominal discomfort, pelvic pain or hypermenorrhea. ${ }^{4}$ In more advanced cases with extra-pelvic involvement, it can mimic a primary cardiac disease. ${ }^{6}$

The preoperative diagnosis of IVL can be suspected when ultrasound detects a uterus with leiomyomas and there is a vascularized thrombus within the pelvic veins and inferior vena cava. ${ }^{3}$ Computed Tomography and MRI are the most useful imaging exams in the diagnosis/evaluation of IVL, ${ }^{8}$ but at the time one does not prevail over the other in diagnostic accuracy. $^{3,6,8}$ This disease appears on the MRI with low to intermediate signal intensity on T1-weighted images, ${ }^{3,8}$ and may demonstrate heterogeneous signal intensity because of the different histological appearance. ${ }^{8}$ It appears as a solid, tubular or "sausage-like" intravascular structure. ${ }^{8}$ Usual CT findings consist of a hypoattenuating intravascular filling defect associated with uterine leiomyomas. ${ }^{8}$ Tumor extension is typically unilateral, and can present two different venous routes: the uterine vein, and, less frequently, the ovarian vein. ${ }^{8}$ Echocardiography may be useful when intracardiac leiomyomatosis is suspected. ${ }^{6}$ However, it is very difficult to diagnose this entity, and the IVL is usually suspected only intraoperatively or after a pathologic analysis. $^{7,9}$ To our knowledge, there are no published IVL cases with a preoperative diagnosis, without extra-pelvic involvement. This entity can be misdiagnosed as a leiomyoma with vascular invasion, a leiomyosarcoma, a bland or a malignant thrombus (from an adrenal tumor, Wilms tumor or metastatic renal cell carcinoma), ${ }^{3,6}$ or even as a uterine leiomyoma with hydropic changes. ${ }^{9}$ Presently, it is not possible to differentiate IVL from leiomyosarcoma based on imaging exams, ${ }^{3}$ and a histological diagnosis is required. When the heart is involved, it can also mimic an atrial myxoma. ${ }^{6}$

The IVL always needs a surgical approach, for diagnosis and treatment purposes. The best treatment option is to make a hysterectomy with a bilateral salpingo-oophorectomy and a complete resection of every intravenous extension of the disease, including intracardiac lesions. ${ }^{4,10}$ In cases of extrauterine invasion, a multidisciplinary team is essential to accomplish the surgery, which is usually performed in two steps, although in some reported cases surgery was performed in a single step. ${ }^{10}$ In one of the largest series reported, Du et al ${ }^{5}$ recommend hysterectomy and unilateral salpingo-oophorectomy in young women without birthing requests, but when there is evidence of a tumor in the extrauterine veins, they recommend a complete resection with hysterectomy, bilateral adnexectomy and excision of the extrauterine tumor with high ligation of ovary veins and arteries. ${ }^{5}$ The main problem emerges in young women who desire fertility preservation, because of the high risk of recurrence when the tumor mass is not completely removed. No published studies approach this issue. $^{6}$

The IVL recurrence rate is not known. Recurrences may present months to several years after the first pelvic surgery. ${ }^{7,8}$ Some publications estimate a recurrence rate of $30 \%{ }^{3}$ Du et al $^{5}$ demonstrate a recurrence rate of $16.6 \%$, and that the risk of recurrence relates to the surgical approach of the disease. Women submitted to hysterectomy with bilateral salpingo-oophorectomy have less probability of recurrence than women submitted to hysterectomy alone or just myomectomy. ${ }^{4,5}$

Pathological findings identify worm-like plugs within the broad ligament, vessels and soft tissue of the lower uterine segment, which, under microscopic examination, are characterized by proliferations of benign smooth muscle cells. ${ }^{5}$ It is essential that pathologists sample the tissues surrounding the myomas (and not only the tumor) and the soft tissue of the lower uterine segment below the peritoneal reflection to identify the early stage of IVL. ${ }^{5}$ These smooth muscle cells are uniform without increased mitotic activity or atypia, ${ }^{7}$ and can show weak to strong expression of progesterone and estrogen receptors. ${ }^{2,4}$ Histological differential diagnosis must be performed with benign and malignant pathologies, like cotyledonoid dissecting leiomyoma, benign metastasizing leiomyomas (BMLs), uterine smooth muscle tumors of uncertain malignant potential (STUMP), leiomyosarcomas or endometrial stromal sarcomas. ${ }^{11}$ Benign metastasizing leiomyoma, IVL and STUMP are benign uterine smooth muscle tumors that can have recurrent and/or metastatic potential, ${ }^{11}$ whereas cotyledonoid dissecting leiomyoma does not. Benign metastasizing leiomyoma is a rare smooth muscle neoplasm that usually affects the lungs in premenopausal women, and it can be associated with IVL. ${ }^{12}$ Benign metastasizing leiomyoma is usually asymptomatic, and it can have expectant management. When it's symptomatic, oophorectomy or antiestrogenic therapy can be used to promote tumor regression. ${ }^{13}$ Some authors believe that BML and IVL may be the same condition in a different stage of the disease. ${ }^{7,14}$ Uterine smooth muscle tumors of uncertain malignant potential are also a rare condition, which presents with some characteristics of sarcomas, without meeting full diagnostic criteria. ${ }^{14}$ The histological classification of STUMP is difficult, and is usually based on Stanford Criteria that combine three features: cell atypia, mitotic rate and type of necrosis. ${ }^{11,14}$ There are few studies on STUMP follow-up and its recurrence rate/clinical behavior, which is why there is no consensus about its treatment. ${ }^{11,14}$ These benign pathologies can have similarities on clinical behavior, but they have some 
important histological differences. Because of their rarity, there is no prevailing consensus about treatment and followup.

Antiestrogenic therapy, like tamoxifen, gonadotropin-releasing hormone agonists, letrozole or medroxyprogesterone, has been used to prevent tumor growth and reduce tumor mass, 5,6,15 but no efficacy has been demonstrated.

Because of the high recurrence risk, long term imaging follow-up is a recommended measure, usually TC or MRI, ${ }^{5,6,8}$ but no limit is set as to how long the surveillance should continue. There is also no consensus about the periodicity of the follow-up: some recommend it once a year or every six months when complete resection is made, ${ }^{6}$ but others recommend a more closely spaced surveillance (every three to six months). ${ }^{3}$

Although it was not possible to diagnose IVL before the surgery, in this reported case it was possible to apply an adequate surgical treatment. In our opinion, based on the review of the literature, women without birthing requests and close to menopause should be submitted to hysterectomy with a bilateral salpingo-oophorectomy, minimizing the recurrence risk (because of the estrogen-dependence of the tumor), ${ }^{4,5}$ especially when it is difficult to exclude extrauterine disease. Once the histological diagnosis was made, different imaging studies were performed to exclude vascular or heart disease, and to assure complete mass resection. After one year of follow-up, the patient remained asymptomatic, without any evidence of recurrence. Even without signs of residual disease, based on some case reports, ${ }^{6,15}$ the patient was kept under continuous progestative treatment in the first year after the surgery to minimize the recurrence risk; the treatment was suspended after this period. The patient will remain in close surveillance, with a yearly image follow-up for at least 10 years. This reported case is very unique because IVL without extra-pelvic extension has received little attention in the reported literature. ${ }^{5}$ Du et $\mathrm{al}^{5}$ published the last review in the English literature on Pubmed, indicating 298 cases of IVL reported until August 2010, 164 of which were without extra-pelvic involvement. Since that date to December 2015, using the key word "intravenous leiomyomatosis", we found 81 papers included by Pubmed, but they mainly report cases with heart or inferior vena cava involvement (65 articles). Only 8 articles report IVL cases without extra-pelvic involvement, with 35 cases in total.

Thus, we can say that until 2015 there were only 199 reported cases of intravenous leiomyomatosis without extra-pelvic involvement.

In conclusion, IVL is a rare condition that can lead to serious, even fatal, complications. This reported case was not diagnosed until surgery, but because of the surgeon's suspicious, it was well conducted, with an exhaustive evaluation, allowing a proper treatment and follow-up.
Diagnosis coupled with an appropriate treatment is very important to patient outcome, because it can reduce the probability of recurrence. Underdiagnoses may be counteracted if the gynecologist is aware of this entity.

\section{References}

1 Wallach EE, Vlahos NF. Uterine myomas: an overview of development, clinical features, and management. Obstet Gynecol 2004; 104(2):393-406

2 Barksdale J, Abolhoda A, Saremi F. Intravenous leiomyomatosis presenting as acute Budd-Chiari syndrome. J Vasc Surg 2011; 54(3):860-863

3 Fasih N, Prasad Shanbhogue AK, Macdonald DB, et al. Leiomyomas beyond the uterus: unusual locations, rare manifestations. Radiographics 2008;28(7):1931-1948

4 Valdés Devesa V, Conley CR, Stone WM, Collins JM, Magrina JF. Update on intravenous leiomyomatosis: report of five patients and literature review. Eur J Obstet Gynecol Reprod Biol 2013; 171(2):209-213

5 Du J, Zhao X, Guo D, Li H, Sun B. Intravenous leiomyomatosis of the uterus: a clinicopathologic study of 18 cases, with emphasis on early diagnosis and appropriate treatment strategies. Hum Pathol 2011;42(9):1240-1246

6 Clay TD, Dimitriou J, McNally OM, Russell PA, Newcomb AE, Wilson AM. Intravenous leiomyomatosis with intracardiac extension - a review of diagnosis and management with an illustrative case. Surg Oncol 2013;22(3):e44-e52

7 Carr RJ, Hui P, Buza N. Intravenous leiomyomatosis revisited: an experience of 14 cases at a single medical center. Int J Gynecol Pathol 2015;34(2):169-176

8 Bender LC, Mitsumori LM, Lloyd KA, Stambaugh LE III. AIRP best cases in radiologic-pathologic correlation: intravenous leiomyomatosis. Radiographics 2011;31(4):1053-1058

9 Clement PB, Young RH, Scully RE. Diffuse, perinodular, and other patterns of hydropic degeneration within and adjacent to uterine leiomyomas. Problems in differential diagnosis. Am J Surg Pathol 1992;16(1):26-32

10 Wang J, Yang J, Huang $\mathrm{H}$, et al. Management of intravenous leiomyomatosis with intracaval and intracardiac extension. Obstet Gynecol 2012;120(6):1400-1406

11 Ip PP, Tse KY, Tam KF. Uterine smooth muscle tumors other than the ordinary leiomyomas and leiomyosarcomas: a review of selected variants with emphasis on recent advances and unusual morphology that may cause concern for malignancy. Adv Anat Pathol 2010;17(2):91-112

12 Lee HJ, Choi J, Kim KR. Pulmonary benign metastasizing leiomyoma associated with intravenous leiomyomatosis of the uterus: clinical behavior and genomic changes supporting a transportation theory. Int J Gynecol Pathol 2008;27(3):340-345

13 Awonuga AO, Shavell VI, Imudia AN, Rotas M, Diamond MP, Puscheck EE. Pathogenesis of benign metastasizing leiomyoma: a review. Obstet Gynecol Surv 2010;65(3):189-195

14 Campbell JE, Knudtson JF, Valente PT, Robinson RD, Kost ER. Successful pregnancy following myomectomy for uterine smooth muscle tumor of uncertain malignant potential: A case report and review of the literature. Gynecol Oncol Rep 2016;15:1-3

15 Barjot PJ, Refahi N, Berthet P, Delautre VD. Intravenous leiomyomatosis of the uterus: a GnRH agonist utilisation before surgery. J Obstet Gynaecol 1998;18(5):492-493 